\title{
Research on the Present Condition and Product Design of Suiling Black Pottery in Heilongjiang Province
}

\author{
Li Xiaoqi $^{1}$, Zhao Aili $^{1 \text { a }}$,Jia Mengshi $^{1}$, Yan Zhenxing ${ }^{1}$,Yang Liangliang ${ }^{1}$ andWang Weijie ${ }^{1}$ \\ ${ }^{1}$ Heilongjiang Bayi Agricultural University, Industrial Design, China
}

\begin{abstract}
The paper surveys and analyzes the basic present condition of Suiling black pottery in Heilongjiang Province, and innovates and designs black pottery products. This paper combines traditional technologies with modern design methods to enrich the categories of black pottery products, expands the industry chain, and promotes the economic development of Suiling. The rapid development of modern industry led to the decline of handicraft, and the development of Suiling black pottery has stagnated. Handicrafts should be designed and transformed to ensure the inheritance of traditional culture and skills.
\end{abstract}

\section{Introduction}

As the birthplace of modern black pottery, Heilongjiang Suiling black pottery has special differences from black pottery in other areas: pure hand-made, natural black by firing, no artificial coloring, matt finished products, good air permeability, good adsorption, black with blue. Suiling black pottery is the artistic treasure of Heilongjiang. In order to carry forward this kind of folk traditional art, black pottery is brought into people's daily life through innovative design, and the black pottery culture of Suiling was appreciated by more people.

\section{Development history of Suiling black pottery}

Black pottery began its development from the Neolithic period. As an important art category in arts and crafts, it has a rich cultural heritage. The foundation and history of black pottery can be traced back to the most primitive stage of human life production. Pottery initially did not exist as arts and crafts; it was first used as a daily use of functional appliances, convenience for people's life, and then had the need to meet the conditions of human aesthetic demand [1].

In the early days, the color of the Suiling black pottery is red, and there were always gray products in the finished product after kiln firing, and the founder of Suiling black pottery, Kou Hualin, solved the black pottery smoking and carburizing technology. The black color of black pottery is formed in the late period of kiln sealing, resulting in insufficient combustion of fireweed and smoky carburization. The formed pottery surface is matt, there is no obvious reflective gloss, and there are a lot of carbon micro particles on the bottle body, showing

\footnotetext{
a Corresponding author: aili_ailie $@$,hotmail.com
}

point crystal clear. Most of the early experiments were grey and a few were black. People tried and innovated to obtain the best temperature and time, and they produced black pottery with pure color.

In 1957, the products produced by the Suiling pottery factory were mainly used for pottery and water pots in people's daily lives, and some simple patterns were painted on the outer surface. In this stage, black pottery products were still in practical pottery. The artistry of the ornamentation needed to be improved, but it bore the artistic spirit of the Suiling people, and reflected the human's pursuit of nature and beauty.

Beginning in 1961, Suiling black pottery received the attention of the famous Mr. Liu Jiadi, and he then organized a number of professional designers to make art direction and creation in Suiling clay pottery factory. [2] This is an important change to the artistic development of Suiling black pottery. By drawing on books, teaching experience and professional pattern design, black pottery has achieved great improvement in artistic value and cultural connotation. Later, the classic double hollowed-out flowerpot was designed and produced by Kou Hualin. The "multi-layer hollowed-out carving" technique in the classic double-layer hollowed-out flowerpot is one of the characteristics of the Suiling black pottery.

So far, the black pottery companies in Suiling still maintain a pure hand-made method. Based on the traditional craftsmanship of Suiling, it has been improved and the type of ware is multiple. The black pottery is black and matte by using the secondary carburizing method.

From the development point of view, Suiling black pottery changed from the completely practical product to the artistic product. In this process, the artistic attainments of black pottery reached a certain height but weakened the practicality of the product. Form follows function, the modelling form of product is indispensable, but practicality is the most basic requirement, artistic 
performance should be based around functional utility. Japan's Liu Zongyue once put forward the view: "The beauty of craftsmanship is the practical beauty. All the beauty comes from the heart of service. When artifacts lose their practical value, they also lose the beauty." [3] The beauty of craftsmanship lies in its practicality, the closer to life, and the more able to embody the beauty of the craftsmanship of the product.

\section{Present condition of Suiling black pottery}

Nowadays, traditional black pottery products in Heilongjiang Province have formed unique aesthetic features and cultural connotations under specific social and natural backgrounds, which are of great research value. Because black pottery has a wide range of raw materials, black pottery develops rapidly. At present, the traditional black pottery market has matured, but there are problems such as the imperfect cultural market mechanism, a single level of product structure, and weak awareness of cultural innovation, which has led to a dilemma of low overall economic efficiency and difficulty in inheriting traditional skills. After a long period of development, Suiling black pottery is still dominated by handicrafts, its characteristics have led to the inability to mass-produce products, high production costs and restriction on consumer groups. At the same time, due to the long production cycle, transportation difficulties and other reasons, the market cannot be opened. Although the art value of Suiling black pottery and Jingdezhen porcelain, Yixing purple sands pottery and other pottery and porcelain are all equal, the popularity of Suiling black pottery is far lower than that of the latter two.

Therefore, it is imperative to adopt transformation design, integrate business models and design processes, transform traditional design thinking into innovative service thinking, and enable research results to exhibit black pottery's artistic features and practicality at the same time, and eventually form black pottery's innovative product design and promotion ideas, to achieve serialization, continuous, personalized development purposes.

\section{Research content}

\subsection{Comparative analysis of black pottery of same kind}

There are many excavation sites of black pottery including: Rizhao, Xingjing, Longshan, and Suiling. The black pottery culture of Suiling is different from the black pottery culture of other regions, and has not been affected by other cultures. Suiling black pottery is completely independent without reference to any other black pottery products. In this paper, the typical Rizhao pottery, Xingjing black sand and Suiling black pottery were selected for comparative analysis, as shown in table 1 .
Table 1. Comparison of Rizhao black pottery, Xinjing black sand and Suiling black pottery.

\begin{tabular}{|c|c|c|c|}
\hline & $\begin{array}{c}\text { Rizhao black } \\
\text { pottery }\end{array}$ & $\begin{array}{c}\text { Yinjing black } \\
\text { sand }\end{array}$ & $\begin{array}{c}\text { Suiling black } \\
\text { pottery }\end{array}$ \\
\hline Type of ware & $\begin{array}{l}\text { Bottle, brick, } \\
\text { tile, cylinder }\end{array}$ & $\begin{array}{l}\text { Pan, pot, } \\
\text { kettle }\end{array}$ & $\begin{array}{l}\text { Bottle, pot, } \\
\text { basin, ball, } \\
\text { tube. }\end{array}$ \\
\hline Pattern & $\begin{array}{l}\text { String, row, } \\
\text { carving. }\end{array}$ & $\begin{array}{l}\text { Dragon and } \\
\text { phoenix lion } \\
\text { fish, orchid } \\
\text { bamboo }\end{array}$ & $\begin{array}{c}\text { Folk paper } \\
\text { cutting, an- } \\
\text { cient auspi- } \\
\text { cious animals } \\
\text { and graphic } \\
\text { symbols, eight } \\
\text { diagram. }\end{array}$ \\
\hline Materials & $\begin{array}{l}\text { Rizhao two } \\
\text { city mud }\end{array}$ & $\begin{array}{l}\text { Black sand } \\
\text { mixed with } \\
\text { Xingjing } \\
\text { Baishan mud } \\
\text { and cinder }\end{array}$ & $\begin{array}{c}\text { Suiling yellow } \\
\text { clay }\end{array}$ \\
\hline Craft & $\begin{array}{c}\text { Nine - layer } \\
\text { mud extrac- } \\
\text { tion method, } \\
\text { water embel- } \\
\text { lish smolder } \\
\text { process, } \\
\text { traditional } \\
\text { swallow - nest } \\
\text { clay. }\end{array}$ & $\begin{array}{l}\text { Shaped moule } \\
\text { with windlass }\end{array}$ & $\begin{array}{l}\text { Hand billet, } \\
\text { hollow carv- } \\
\text { ing. }\end{array}$ \\
\hline
\end{tabular}

Rizhao black pottery: the production process used by Rizhao black pottery is nine - layer mud extraction, water embellish smolder process, traditional swallow - nest clay. Rizhao black pottery adopts the two city mud with the unique characteristics of fine color and purity. Rizhao black pottery is fired from the original earth kiln, and the ceramic ware is fine and polished with a dark and shiny surface. Rizhao black pottery is mostly vases, plane reliefs, sculptures, and various crafts. Rizhao black pottery is less decorative, mostly plain polished. The patterns are only bow string pattern, dermographic and hollow decoration.

Xingjing black sand: the shape of Xingjing sander is round and thick and full of shape. It is made of black sand mixed with Xingjing Baishan mud and cinder. The texture of this kind of black sand is coarse, the grain feel is more obvious. Xingjing black sand mainly consists of two types, one is traditional modeling, the other is modern modeling. The traditional modelling is mainly casserole, modern modelling is tea set, sculpture handicraft and so on. Xingjing black sand production is made by using the mould and windlass. The decorative patterns on the surface are generally the folk styles of dragon, phoenix, lion, fish, orchid, bamboo and chrysanthemum.

Suiling black pottery: Suiling black pottery has different varieties according to different classification standards, which can be divided into more than twenty kinds of bottle, pot, basin, ball, tube. The inspiration of the decoration is mainly from the folk paper-cut and the carved patterns on the box, mainly for the ancient auspicious animals, auspicious symbols and the eight diagrams. The yellow clay unique to Suiling makes the black pottery black and matt with blue. One of the characteristics of the Suiling black pottery is exquisite hollow carving technique, openwork carving pattern.

\subsection{User and market analysis}

We did a survey which was conducted on black pottery products and other pottery products. The survey covered 
products cognition, promotion channels, purchase channels, and consumer demand of black pottery. The analysis contents are shown in Table 2.

Table 2. User survey and analysis

\begin{tabular}{|c|c|c|c|}
\hline & Collector & Middle-class & $\begin{array}{c}\text { General } \\
\text { consumer }\end{array}$ \\
\hline Feature & $\begin{array}{l}\text { Value the } \\
\text { artistic } \\
\text { value of the } \\
\text { product }\end{array}$ & $\begin{array}{l}\text { Value the cul- } \\
\text { tural connotation } \\
\text { of products }\end{array}$ & $\begin{array}{l}\text { Value the } \\
\text { practicality of } \\
\text { the product } \\
\text { and appear- } \\
\text { ance }\end{array}$ \\
\hline $\begin{array}{c}\text { Purchasing } \\
\text { power }\end{array}$ & High & Medium & Low \\
\hline $\begin{array}{l}\text { Economic } \\
\text { capability }\end{array}$ & Strong & Medium & General \\
\hline
\end{tabular}

After investigation, it was found that more than 50\% of the population had no knowledge of the black pottery, and most of the people who had heard of the Suiling black pottery were Suiling locals. This result fully shows that the government of the black pottery origin and the black pottery producers and sales staff has paid insufficient attention to black pottery propaganda. They did not publicize and promote the traditional black pottery products through effective propaganda methods, which greatly limited the development and inheritance of black pottery.

In terms of purchasing, most consumers will choose to buy in the mall or through the Internet. The price of the specialty stores is generally higher and fewer people choose to buy through it. This also shows the importance of online advertising. The analysis shows that most of the black pottery products purchased by consumers are used for daily life. The existing black pottery products are mostly handicrafts, which are used for decoration or collection. The black pottery manufacturers need to increase the existing product categories for the market demand, and improve the practicality of the products. The statistics show that the consumer demand of black pottery products is small and the purchasing power is low. The main reason for this problem is that the product positioning of Suiling black pottery is too high, and the black pottery industry needs to increase the middle and low-end products and expand the consumer group.

In terms of product style, the styles that modern people generally appreciate are simple and fresh, and the existing styles are complicated, and the carvings are hollow and delicate, which are more suitable as art collections and should be adjusted to meet the needs of consumers. Through data analysis, we can find that consumers in today's society pay more attention to their own inner and spiritual needs. In addition to the value of appearance, the cultural connotation of products has become more and more important.

Surveys show that, although consumers know little about black pottery and related products, they have more understanding of other pottery or ceramic products and can analyze black pottery and related products by drawing on consumers' attitudes and opinions on similar products. Consumers are in expectation of black pottery products with both artistic value and practicality.

\subsection{Field investigation}

During the study, two black pottery production companies were visited in Suiling County, Heilongjiang Province. The sales channels of Suiling black pottery in Heilongjiang Province are very single, mainly by offline entity store, followed by sales agents. Since the production of black pottery is all made by hand, the production cycle is long, the temperature and humidity are strict, and the accidental burst in the process of boiling makes black pottery a rare and undemanding product. In a total cost-to-profit ratio of finished black pottery products, handcrafting accounted for $46 \%$, electricity bills, transportation, preservation, etc. accounted for $30 \%$, so the profit of black pottery was very small. Such conditions make the price of black pottery remain high.

In the process of on-the-spot investigation, we found that the presence of counterfeiting manufacturer, in order to reduce cost, shorten production cycle, they moved black pottery to the batch production line, used rough and inferior molds to make fake black pottery, using paint color dark shiny effect. The defective products that have been fired are masked by artificially colored cracks with rough technique. Black pottery is difficult to identify, without its own standards. Compared with other art value less than the black pottery products, the market is not standardized and orderly.

The production cycle of Suiling black pottery is long and the production process is complex. The selection and preparation of materials will take three to four months. First, the yellow clay will be added to the water to be crushed and stirred, filtered and precipitated, and then the clay bar will be drawn. This process will screen the small stones in the clay completely, preventing them from cracking and breaking the surrounding pottery in the process of firing. Then, the throwing is drawn; the throwing is dried to the point where it can be hand-carved. During this process, there will be at least two times of polishing, so that the ceramic body will become smooth and perfect. After the hand carving is finished, the drying stage is carried out. The drying stage is divided into three parts: dry, medium and warm drying, high temperature dries, it takes three weeks. After the drying is completed, firing is performed. The firing takes $12-15$ hours and the temperature is between $700-1000^{\circ} \mathrm{C}$.

In this condition, every black pottery product that is fired is a blend of utensils and ingenuity. Exquisite hollow carving reveals the sentiments of artisans. The artifacts produced on the industrial assembly line can achieve the same level of refinement, but the product is soulless, and artistic value and cultural connotation are not as good as traditional handmade products.

\section{Innovation path analysis}

In order to solve the problem of small scale, single product variety and low practicability, it is necessary to change the product positioning problem in the industry. The products of black pottery are located in high-end art collections, high-end souvenirs and high-end gifts, which limited the market [3]. We should enrich the production line of black pottery and expand the coverage rate of consumers. 
In the past, the black pottery product positioning is a work of art, the practicality of art is low, and the collection is high. Consumers are different from art collectors. Consumers are more concerned with the practicality, quality and cost performance of products, while collectors value the artistic value of products. With economic development, commodities are no longer simply easy to use and have more added value, such as brand value and cultural connotation. More and more consumers are willing to purchase products with cultural added value to enhance their aesthetic and taste. Consumers want commodities to bring more meaning to manifest their value.

The surface of the black pottery is matte, the bottle is black and elegant, and there will be streamers in the light. Chosen materials and unique firing technology makes the black pottery itself is able to adjust the humidity of the indoor environment. Such features can be applied to the office products to provide clean air and comfortable environment for users. The color of black pottery is a quiet, simple but elegant, the appearance model is decorated with rich and varied and cultural ornamentation, which can reflect the cultural connotation of black pottery and fully integrate into the office environment. In addition, the black pottery hollow carving technology is mature, it is used in the design of candlesticks, fragrance lamps and other home products, the traditional handicrafts are given a second meaning. At the same time because of the influence of firing techniques, black pottery has activated carbon adsorption. In this severe environment of air pollution, everyone pays more attention to physical health and environmental conditions. Black pottery products with green features will regulate the relationship between people and the environment, improve the quality of human life, and promote the harmonious development of people and the environment. This kind of product with both practicality and strong cultural connotation can enable people to come into contact with the traditional art of the Chinese nation, bring more artistic influence to people, and make the national culture more widely spread.

Therefore, based on the production process of black pottery, the characteristics of the materials and the characteristics of the finished product, the product target population of Suiling black pottery and the current market supply and demand relationship are analyzed, the existing black pottery products are improved, black pottery is matched with other materials, and the external decoration is simplified. Designing the same product that is mainly based on decorative features, removing the original complex decorative carvings, the appearance is simple and elegant, easy to match with the modern living room, in line with modern aesthetic needs. The quality of the black pottery products is an improvement for the home environment. More practicable and artistically balanced products can change the condition of Suiling black pottery, increase product variety, increase awareness, and bring more economic benefits.

\section{Innovative product designs}

According to the previous research, the innovative product design was carried out. In view of the material char- acteristics of black pottery, black pottery materials are used as part of the product for the characteristics of products. At the same time, black pottery has the same adsorption as activated carbon. This kind of green and environmental protection features, under the severe environment of the current air pollution problem, everyone pays more attention to physical health and environmental conditions, and black pottery products will undoubtedly receive customers' appreciation. This kind of product with both practicality and strong cultural background will attract more consumer groups, change the present situation, increase product variety, increase popularity, and bring more economic benefits. The black pottery product category is positioned as fragrance lamps, table lamps, vases, etc. The following are design examples.

\subsection{Fragrance candlestick of black pottery}

Fragrance candlestick is used more commonly in people's life; it is a kind of common household goods. The market share of fragrance candles added essential oil with different functions is growing. According to 2016 report, the retail market for American household fragrances is about $\$ 6.4$ billion. A kind of candlestick designed with black pottery is used in combination with fragrance candle. A candle is placed on the upper part, and an electronic watch that can display the time is on the lower part. There are two functions of storing the candle and serving as a watch. The shape is a cylinder with rounded edges. There is no ornamentation on the device, the appearance is simple, and the material characteristics of the black pottery are fully displayed, as shown in Figure 1.
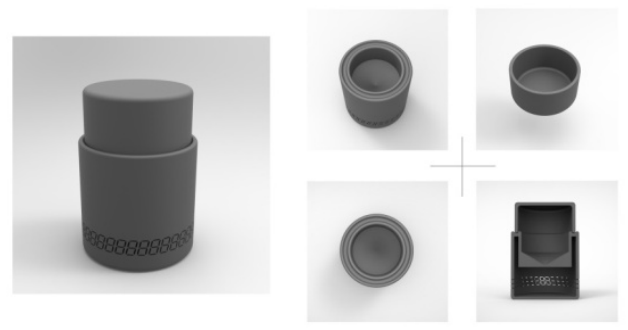

Figure 1. Fragrance candlestick of black pottery

\subsection{Pottery charm—black pottery decoration}

"Pottery charm" black pottery decoration is a fine work combining traditional Suiling black pottery and modern design ideas. The main materials are black clay, pine and glass. The decoration material is simple and unsophisticated, and the structure is simple and bright. It is suitable for home furnishing, flower arrangement and other usage. The production process of the product is very exquisite from the materials selection. Each processing step is to express the beauty of the essence of black pottery. The unique design idea makes the decoration possess the traditional wisdom and the modern beauty, and it also has a touch of Zen thought in use. The traditional black pottery material makes it full of Zen, such as the trees in the tranquil temple, which is always silent and full of wis- 
dom. See Figure 2.

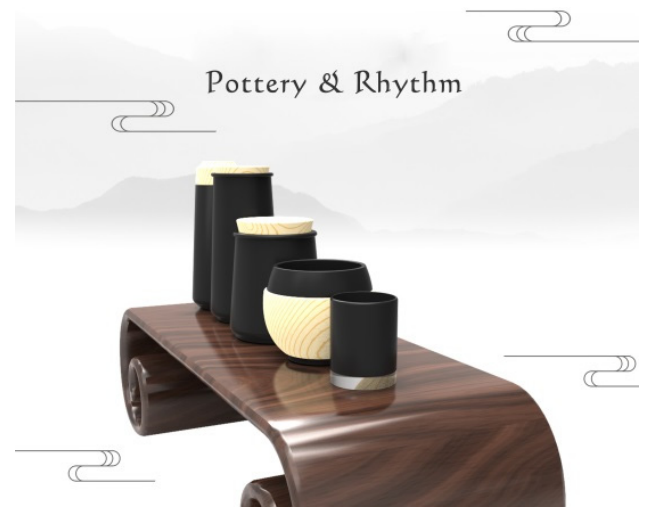

Figure 2. "Pottery charm" black pottery decoration

\section{Conclusions}

The ingenious spirit and cultural value represented by the Suiling black pottery are incomparable with other similar products. Suiling black pottery still maintains the pure hand craft, which is particularly valuable in the modern mechanized production atmosphere. A Japanese said, "the fundamental difference between a hand and a machine is that the hand is connected to the heart, and the machine has no heart." Each of the Suiling black pottery is integrated into the emotions of the workers, and the cultural value experience cannot be replaced by the mechanized production. The innovative design of black pottery products enables the process characteristics to be reflected, which is more practical. It transforms traditional handicrafts and returns to people's daily lives, deepens people's understanding of traditional crafts, and makes the hand-made spirit and traditional national culture better inherited.

\section{Acknowledgment}

This thesis is from Heilongjiang Bayi Agricultural University's national undergraduate innovation training program. (Project number: 201710223021)

\section{References}

1. Kaihong Wang. On the Development of Modern Black Pottery Culture Ecology under the Perspective of "Non-heritage" [d]. Northeast Normal University (2016).

2. Jiali Liu. A Review of the Suiling Black Pottery [J] Decoration, 1998 (06) :52-54.

3. Zongyue Liu. The Way of Craft [M] Guilin: Guangxi Normal University Press, (2011)

4. Xiao He. Rizhao Black Pottery Craft and Artistic Survival [J] Art and Design (Theory), 2017, 2(05): 124-126. 